\title{
Polarization and Breakdown Analysis of AlGaN Channel HEMTs with AlN Buffer
}

\author{
Godwin Raj1*, Mohan Kumar², Chandan Kumar Sarkar1 \\ ${ }^{1}$ Nano Device Simulation Laboratory, Electronics and Telecommunication Engineering Department, Jadavpur \\ University, Kolkata, India \\ ${ }^{2}$ SKP Engineering College, Tiruvannamalai, India \\ Email: ${ }^{*}$ godwinraj123@gmail.com
}

Received 30 January 2015; accepted 18 August 2015; published 21 August 2015

Copyright (C) 2015 by authors and Scientific Research Publishing Inc.

This work is licensed under the Creative Commons Attribution International License (CC BY).

http://creativecommons.org/licenses/by/4.0/

(c) (i) Open Access

\begin{abstract}
We have demonstrated the first carrier density model for AIGaN channel with AlN buffer using spontaneous and piezoelectric polarization comparison with experimental and theoretical results. From the results we proved that the formation of 2DEG in undoped structure relied both on spontaneous and piezoelectric polarization. The electron distribution of Al concentration $(0<x<0.5)$ was measured for both AlGaN channel and barrier. Barrier thickness assumed between 20 and 25 $\mathrm{nm}$ for validating the experimental results. The carrier concentration was observed at the specific interface of the $\mathrm{N}$ - and Ga-face by assuming $x_{1}, x_{2}=0$. The model results are verified with previously reported experimental data.
\end{abstract}

\section{Keywords}

AlGaN Channel, Sheet Carrier Concentration Model, N- and Ga-face, Polarization, High Breakdown, Total Induced Net Interface Polarization

\section{Introduction}

GaN based HEMTs (High Electron Mobility Transistors) are promising candidates because of their attractive physical properties of higher breakdown electric field, high band gap energy, high frequency operation and high power density. After several attempts, $\mathrm{AlGaN} / \mathrm{GaN}$ based devices proved its maximum frequency and extreme power density [1] [2]. Compared to $\mathrm{Si}$, the $\mathrm{GaN}$ breakdown field is 10 times higher, the band gap is 3 times higher and saturation velocity is 3 times higher. AlN breakdown electric field is 4 times higher, thermal conductance is 1.5 times higher and bandgap is about 2 times higher compared to $\mathrm{GaN}$ [3]. Incorporation of $\mathrm{Al} \%$ in the

"Corresponding author.

How to cite this paper: Raj, G., Kumar, M. and Sarkar, C.K. (2015) Polarization and Breakdown Analysis of AlGaN Channel HEMTs with AIN Buffer. World Journal of Condensed Matter Physics, 5, 232-243.

http://dx.doi.org/10.4236/wjcmp.2015.53024 
channel makes device high breakdown and high temperature operation for next generation high power semiconductor devices. There are few papers reported with $\mathrm{AlGaN}$ as a channel material [4]-[10]. $\mathrm{Al}_{0.51} \mathrm{Ga}_{0.49} \mathrm{~N}$ channel and $\mathrm{Al}_{0.86} \mathrm{Al}_{0.14} \mathrm{~N}$ barrier proved the maximum breakdown voltage $(1800 \mathrm{~V})$ with reduced drain current dispersion. Free standing AlN buffer was used because both substrate materials like Sapphire and $6 \mathrm{H}-\mathrm{SiC}$ suffered from a lattice mismatch with AlGaN channel [11]. Recently, Wei et al. reported Ultra low DIBL (Drain Induced Barrier Lowering). Coefficient of $6.7 \mathrm{mV} / \mathrm{V}$ reported with $\mathrm{Al}_{40} \mathrm{Ga}_{60} \mathrm{~N} / \mathrm{Al}_{18} \mathrm{Ga}_{82} \mathrm{~N}$ HEMT devices. Also this combination attributed to the poor 2DEG confinement [12]. Optimization of AlGaN channel HEMT expected to get high performance in the breakdown and power applications. Wurtzite III-V AlGaN with GaN HEMT device was able to achieve $10^{13} / \mathrm{cm}^{2}$ electron density without doping barrier region. Strained AlGaN/ GaN HEMT was also capable of enhancing carrier density in the quantum well because of spontaneous and piezoelectric polarization charge.

\section{Device Description}

As of previous results AlGaN-channel HEMT with AlN substrates proved lowest dislocation density of $10^{6} / \mathrm{cm}^{2}$ [13]-[15]. In this study, weanalyzed the Polarization properties of AlGaN channel with AlGaN barrier on AlN buffer and AlN/Sapphire Substrate.

Figure 1 shows the schematic structure of low Al composition channel and barrier with $x<0.5$. Thickness of AlN buffer layer assumed as per the critical thickness of $1.2 \mu \mathrm{m}$. AlGaN channel placed above the buffer with 600 $\mathrm{nm} .25 \mathrm{~nm}$ thickness of the AlGaN barrier placed above the channel. The AlN buffer was used for high quality growth.

In this article we focus on device characterization and polarization of Nface and Ga face AlGaN/AlGaN (AlGaN channel) heterostructures. Formation of 2DEG using spontaneous and piezoelectric polarization for varying mole fraction $x_{1}$ and $x_{2}$ (N face and Ga face) analyzed using models and experimental comparison. So we concentrate on the polarity of AlGaN barrier and channel for $2 \mathrm{DEG}$ confinement. We assume $x_{1}=0$ for Nface and $x_{2}=0$ for Ga face to verify the results with Ambacher et al. [16] the Elastic and elastic constants taken from the same paper.

Even though the thickness $\mathrm{AlGaN}$ barrier assumed as $250 \mathrm{~A}^{\circ}$ the confined charge density is higher as compared to GaN HEMT. Device grown on AlN buffer and sapphire substrate because the lattice mismatch between Substrate and $\mathrm{AlGaN}$ channel as we have seen above. The critical thickness and strain relaxation is the key role for AlGaN channel HEMT devices because AlGaN partially relaxed with AlN buffer region [17]. This relaxation assumes in our model as per the experimental results and $\mathrm{Al}$ composition up to 0.5 assumed in our model for barrier and channel region. Lattice constant assumed for AlGaN channel and barrier regions.
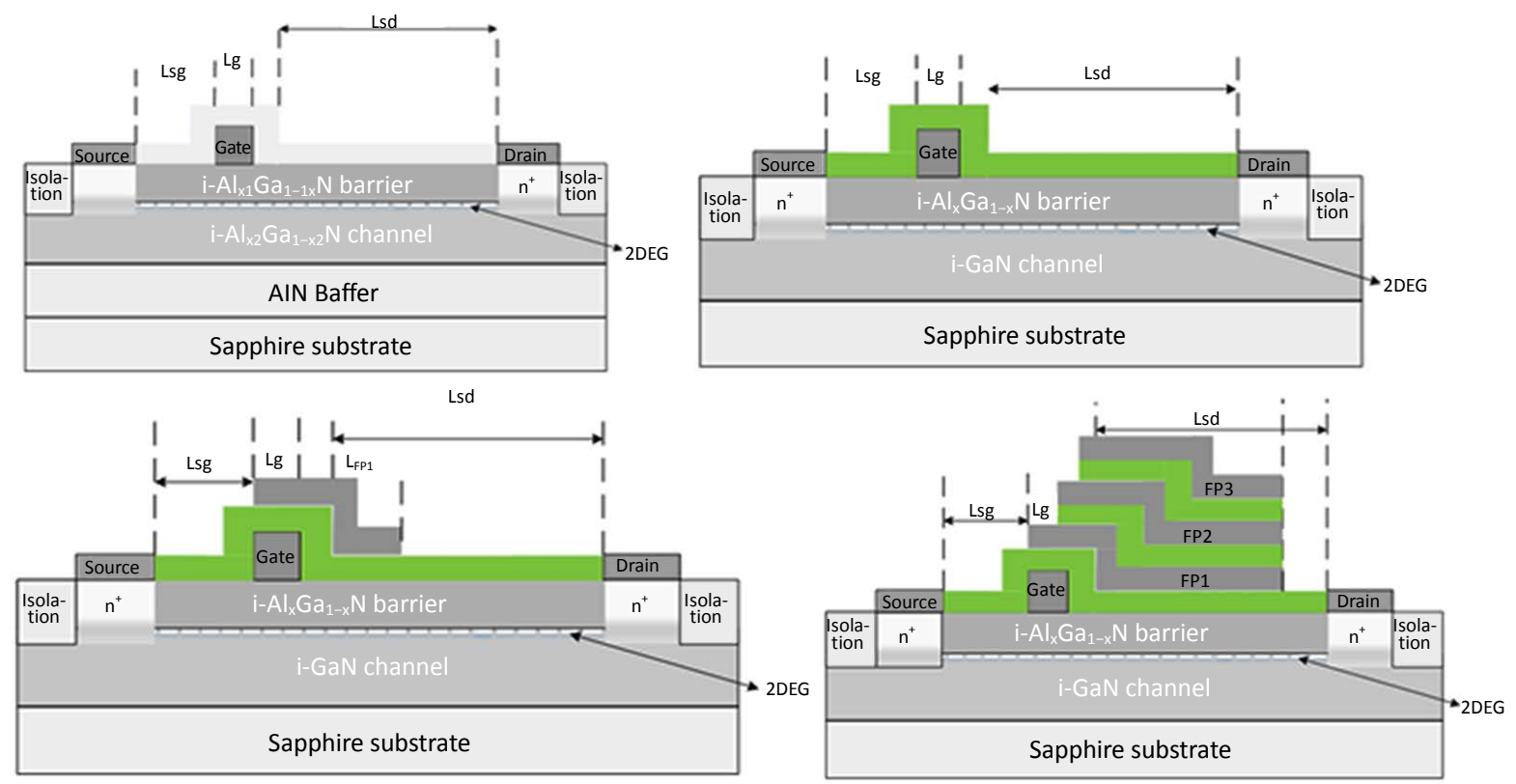

Figure 1. Schematic structure of an AlGaN/AlGaN/AIN HEMT with and without field plate. 
The spontaneous and piezoelectric polarization induced charge density calculated for Pseudomorphic grown hetero devices not considered separately because we assumed AlGaN partially relaxed with barrier as per the composition and experimental data's. The relaxation rate assumed as per experimental comparison later.

Even anundoped barrier can confine carrier density 2DEG in the channel because of the high structural quality interface between $\mathrm{AlGaN}$ channel and buffer region. $\mathrm{C}-\mathrm{V}$ profile measurement assumed the well known technique for measuring the carrier concentration at room temperature. The model used for $\mathrm{C}-\mathrm{V}$ measurement is given below [16]

$$
N_{c-v}=\frac{C^{3}}{e \varepsilon_{0} \varepsilon} \frac{\mathrm{d} V}{\mathrm{~d} C},
$$

Here $C$ is the capacitance per unit area, $V$ is the applied voltage at the gate to barrier interface, $\varepsilon$ is the dielectric constant of the material $\left(\varepsilon_{0}=8.854 \times 10^{-14} \mathrm{C} / \mathrm{V} \mathrm{cm} ; e=1.602 \times 10^{-19} \mathrm{C}\right)$.

The main consequences of model and experimental comparison arise

1) How the Piezo electric polarization occurs in $\mathrm{AlGaN}$ channel and the barrier interface.

2) Why the carrier concentration based on the relaxation of these two interfaces.

To answer these questions we should understand the role and physical properties of spontaneous and piezoelectric polarization.

\section{Spontaneous and Piezoelectric Polarization}

The polarization charge relaxed, tensile strained and compressively strained layer shown in Figure 2 for Ga, $\mathrm{N}$ face heterostructures. In Ga face tensile strained region, spontaneous and piezoelectric polarization assumed to be parallel and compressively strained region, Polarization is antiparallel. This polarization reverses for $\mathrm{N}$ face polarization. Here three AlGa Nregions assumed with composition of $x_{1}, x_{2}$ and $x_{3}$. For validate our results with Ambacher et al. for $\mathrm{Ga}$ and $\mathrm{N}$ face [16] we assumed $x_{1}$ and $x_{3}$ to $0(\mathrm{GaN})$.
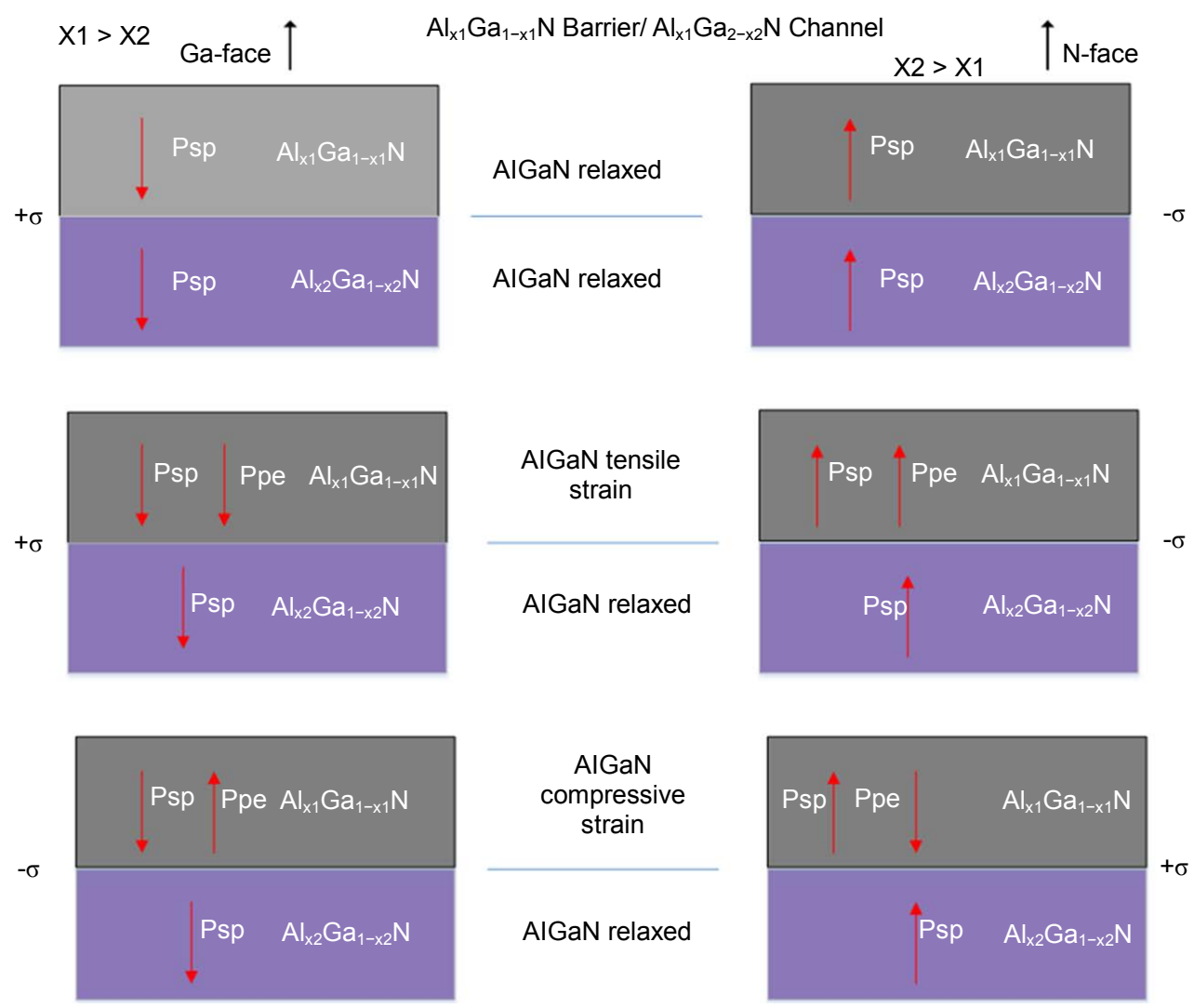

Figure 2. Spontaneous and piezoelectric induced charge in Ga and $\mathrm{N}$ face $\mathrm{AlGaN} / \mathrm{AlGaN}$ heterostructures. 
The total confined charge $\sigma_{\text {int }}$ at $\mathrm{AlGaN} / \mathrm{AlGaN}$ interface is the sum of spontaneous polarization $P_{s p}$ and strain induced piezoelectric polarization at the interface of AlGaN channel. Spontaneous polarization is mainly increased by the Al difference between a barrier and channel region. Spontaneous polarization assumed in [0001] plane. Piezoelectric polarization mainly depends on the strain relaxation occurred between interfaces. It can be modelled by Elastic coefficient $e_{31}, e_{33} . e_{15}$ is sheer strain induced by piezoelectric polarization is not incorporated here. Hexagonal lattice constant of $\mathrm{AlGaN} / \mathrm{AlGaN}$ is given by

$$
P_{P E}=2 \cdot((\text { a_AlGaN_ch/a_AlGaN_br })-0.93)\left[e 31 \_b r-\frac{e 33 \_b r \cdot c 13 \_b r}{c 33 \_b r}\right]
$$

where $c_{33}$ and $c_{11}$ are the elastic constants. The total polarization induced by piezoelectric polarization at Al$\mathrm{GaN} / \mathrm{AlGaN}$ interface is given by

$$
\left\{\begin{array}{l}
c_{13}-\mathrm{br}=\left(5 x_{1}+103\right) \\
c_{33}-{ }^{\mathrm{br}}=\left(-32 x_{1}+405\right) \\
c_{13} \mathrm{ch}=\left(5 x_{2}+103\right) \\
c_{33} \mathrm{ch}=\left(-32 x_{2}+405\right)
\end{array}\right.
$$

Elastic coefficient parameters for AlGaN channel is given by

$$
\left\{\begin{array}{l}
e_{31}{ }^{\mathrm{br}}=\left(-11 x_{1}-0.49\right) \\
e_{33}{ }_{31} \mathrm{br}=\left(0.73 x_{1}+0.73\right) \\
e_{31} \mathrm{ch}=\left(-11 x_{2}-0.49\right) \\
e_{33}{ }_{-} \mathrm{ch}=\left(0.73 x_{2}+0.73\right)
\end{array}\right.
$$

Lattice constant for AlGaN channel and barrier is given by

$$
\begin{aligned}
& \text { a_AlGaN_br }=\left(3.189-0.077 x_{1}\right) 10^{-10} \mathrm{~m} \\
& \text { a_AlGaN_ch }=\left(3.189-0.077 x_{2}\right) 10^{-10} \mathrm{~m}
\end{aligned}
$$

Spontaneous polarization is given by

$$
\begin{aligned}
& \text { Psp_AlGaN_br }=\left(-0.52 x_{1}-0.029\right) \\
& \text { Psp_AlGaN_ch }=\left(-0.52 x_{2}-0.029\right)
\end{aligned}
$$

Total polarization induces a charge for $\mathrm{N}$ face and Ga face is given by Figure 3 and Figure 4 .

Strain induced charge is the main source of carrier concentration in AlGaN/GaN heterostructures. Piezoelectric polarization of AlGaN channel and barrier can be modelled with a single strain relax at the interface. The confined charge density with spontaneous and piezoelectric polarization charge density is given by

$$
\text { Psp_tot }=[\text { Psp_AlGaN_br }- \text { Psp_AlGaN_ch }]
$$

Piezoelectric polarization uses the elastic parameters from Equations (3) and (4)

$$
\begin{aligned}
& \text { Ppz_AlGaN_br }=-2 \cdot(1-\operatorname{strainrelax}) \cdot \operatorname{strain}\left[e_{31}-\mathrm{br}-\frac{e_{33}-\mathrm{br} \cdot c_{13}-\mathrm{br}}{c_{33}-\mathrm{br}}\right] \\
& \text { Ppz_AlGaN_ch }=-2 \cdot(1-\operatorname{strainrelax}) \cdot \operatorname{strain}\left[e_{31} \_\mathrm{ch}-\frac{e_{33}-\mathrm{ch} \cdot c_{13} \_\mathrm{ch}}{c_{33} \_\mathrm{ch}}\right] \\
& \text { Ppz_tot }=\text { Ppz_AlGaN_br }-\mathrm{Ppz} \_ \text {AlGaN_ch } \\
& \sigma(x)=[\text { Psp_tot }+ \text { Ppz_tot }]
\end{aligned}
$$




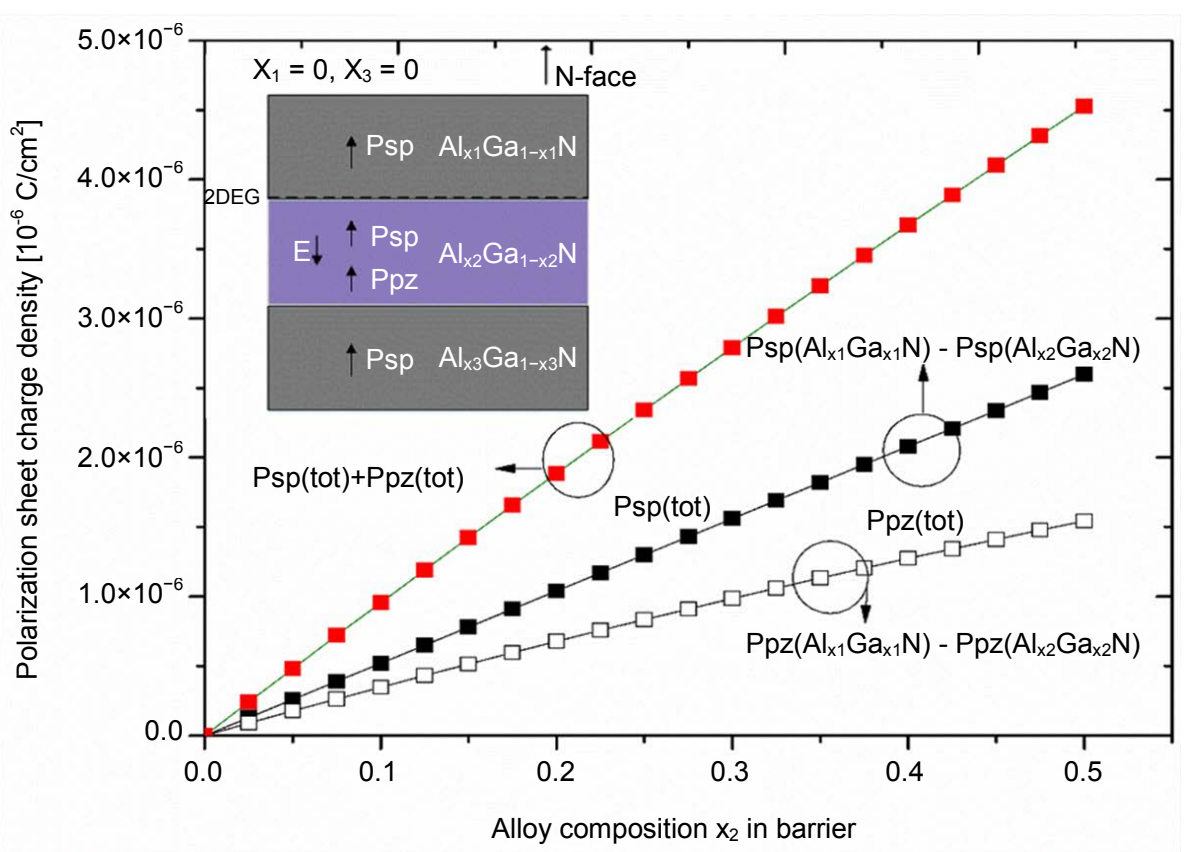

Figure 3. Piezoelectric and spontaneous polarization charge density for various AlGaN barrier alloy compositions for $\mathrm{N}$ face $\mathrm{Al}_{\mathrm{x} 1} \mathrm{Ga}_{1-\mathrm{x} 1} \mathrm{~N} / \mathrm{Al}_{\mathrm{x} 2} \mathrm{Ga}_{1-\mathrm{x} 2} \mathrm{~N} / \mathrm{Al}_{\mathrm{x} 3} \mathrm{Ga}_{1-\mathrm{x} 3} \mathrm{~N}$ heterostructures.

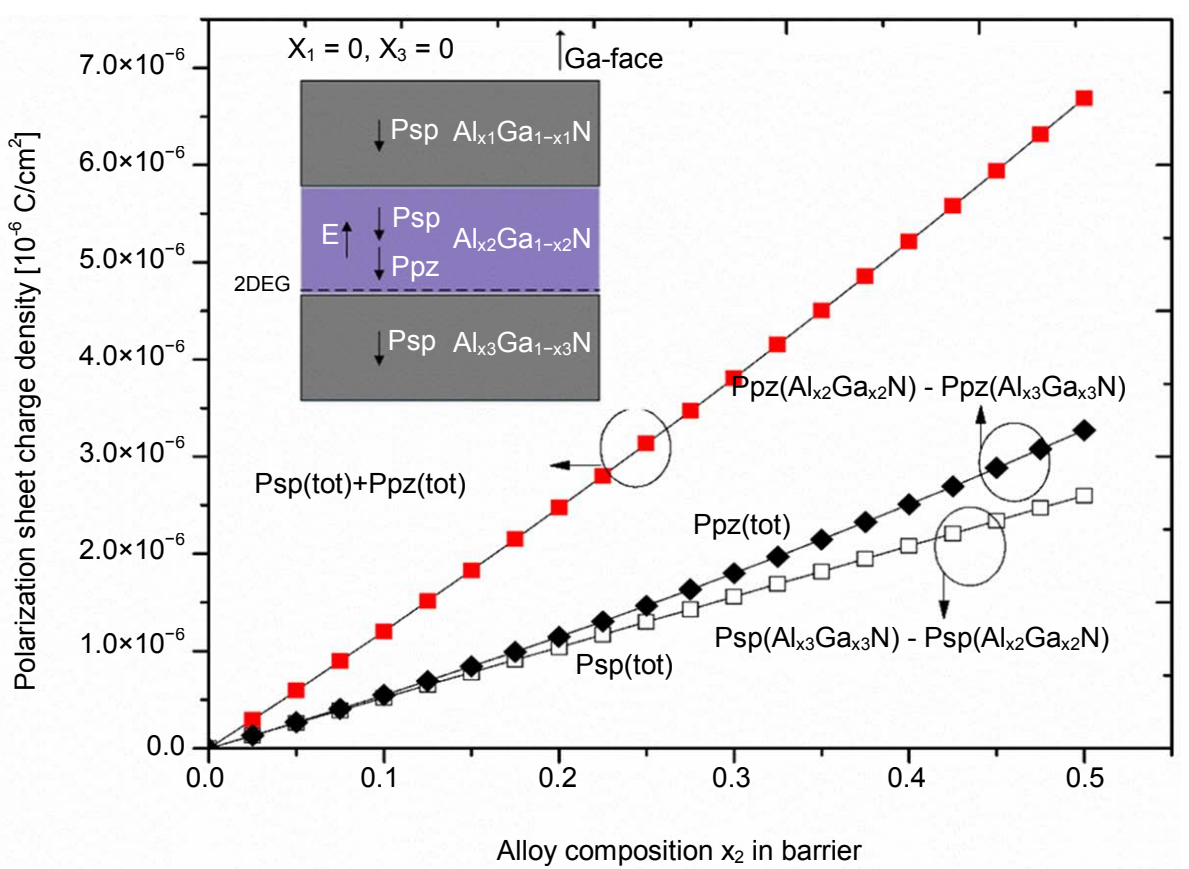

Figure 4. Spontaneous and Piezoelectric polarization charge density for various AlGaN barrier alloy compositions for Ga face $\mathrm{Al}_{\mathrm{x} 1} \mathrm{Ga}_{1-\mathrm{x} 1} \mathrm{~N} / \mathrm{Al}_{\mathrm{x} 2} \mathrm{Ga}_{1-\mathrm{x} 2} \mathrm{~N} / \mathrm{Al}_{\mathrm{x} 3} \mathrm{Ga}_{1-\mathrm{x} 3} \mathrm{~N}$ heterostructures.

\section{Relaxation Rate}

The degree of relaxation $r(x)$ was calculated by

$$
\gamma=\frac{\mathrm{a}_{-} \mathrm{AlGaN} \_\mathrm{ch}-\mathrm{a} \_\mathrm{AlGaN}_{-} \mathrm{br}}{\mathrm{a}_{-} \mathrm{AlGaN} \_\mathrm{ch}^{(0)}-\mathrm{a}_{-} \mathrm{AlGaN}_{-} \mathrm{br}^{(0)}}
$$


Here a_AlGaN_ch ${ }^{(0)}$, a_AlGaN_br ${ }^{(0)}$ are the zero strain lattice constant. a_AlGaN_ch, a_AlGaN_br are the measured lattice constant parameter [17]. Strain relaxation first observed for $200-250 \mathrm{~A}^{\circ}$. The degree of relaxation increased by increasing $\mathrm{Al}$ composition in the barrier this leads to reduction of piezoelectric polarization. The approximated strain relaxation model for inducing charge given by

$$
\gamma= \begin{cases}0.48 & 0<x_{1}<0.4 \\ 0.6 x_{1}+0.02 & 0.4<x_{1}<0.53\end{cases}
$$

\section{Carrier Concentration Model}

An electron from barrier tends to compensate at $\mathrm{AlGaN} / \mathrm{AlGaN}$ interface for $\mathrm{Ga}$ ( $\mathrm{Al}$ or $\mathrm{N}$ face). The confined carrier density for undoped device structure combination is given by [16]

$$
n(x)=\frac{\sigma(x)}{e}-\left(\frac{\varepsilon_{0} \varepsilon(x)}{\mathrm{d}_{-} \mathrm{AlGaN} \cdot e^{2}}\left(e \Phi_{b}(x)+E_{f}(x)-\Delta E_{c}\right)\right)
$$

Here $\varepsilon(x)$ is the dielectric constant, $e \Phi_{b}$ is the gateSchottky-barrier height for $\mathrm{Al}_{\mathrm{x} 1} \mathrm{Ga}_{1-\mathrm{x} 1} \mathrm{~N}$ and gate interface,

$$
\begin{aligned}
& \varepsilon(x)=(-0.5 x 1)+9.5 ; \\
& e \Phi_{b}(x)=(1.3 x 1+0.84) \mathrm{eV} ;
\end{aligned}
$$

Total carrier confined in 2DEG Channel in Ga and N Face calculated using Equation (11) shown in Figure 5.

Here $E_{f}$ is the Fermi energy level with respect to the $\mathrm{Al}_{\mathrm{x} 2} \mathrm{Ga}_{1-\mathrm{x} 2} \mathrm{~N}$ channel, $e$ is the charge of the electron, $d$ is the thickness of the barrier.

$$
\left\{\begin{array}{l}
E_{g}(\mathrm{AlN})=6.13 \mathrm{eV} ; \\
E_{g}(\mathrm{GaN})=3.42 \mathrm{eV} ; \\
E_{g}\left(\mathrm{AlGaN} \_b r\right)=x_{1} E_{g}(\mathrm{AlN})+\left(1-x_{1}\right) E_{g}(\mathrm{GaN})-x_{1}\left(1-x_{1}\right) 1.0 \mathrm{eV} ; \\
E_{g}\left(\mathrm{AlGaN} \_\mathrm{ch}\right)=x_{2} E_{g}(\mathrm{AlN})+\left(1-x_{2}\right) E_{g}(\mathrm{GaN})-x_{2}\left(1-x_{2}\right) 1.0 \mathrm{eV} ; \\
\Delta E_{c}=0.7\left[E_{g}(\mathrm{AlGaN} \text { br })-E_{g}\left(\mathrm{AlGaN} \_\mathrm{ch}\right)\right] \mathrm{eV} ;
\end{array}\right.
$$

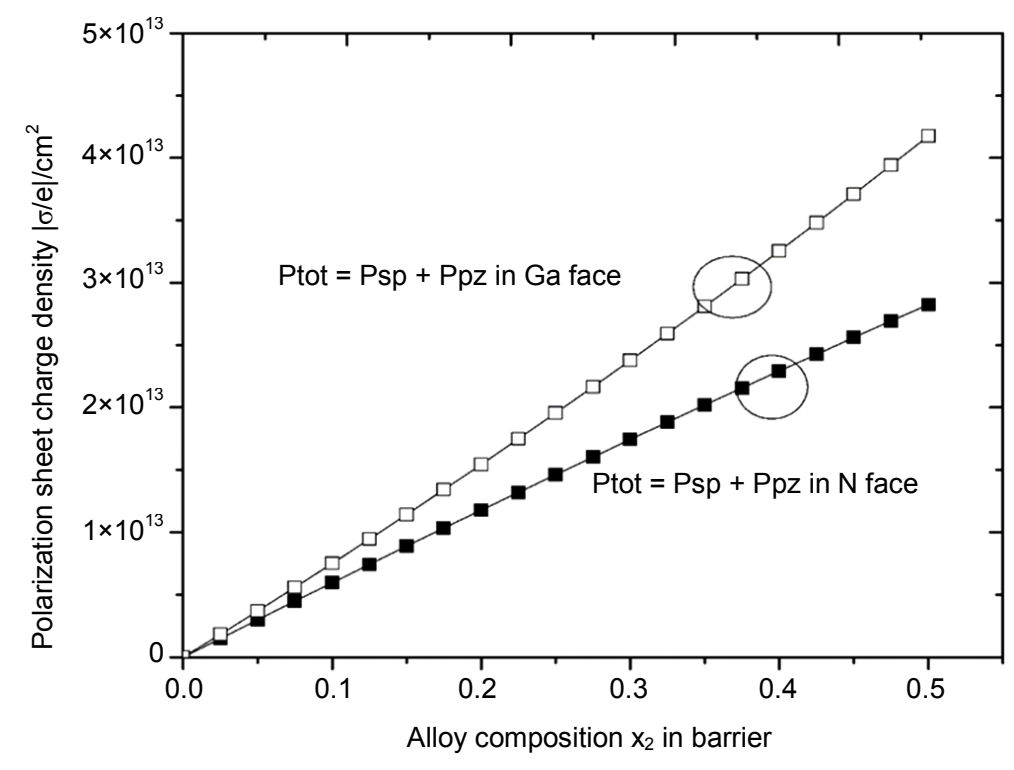

Figure 5. Total polarization charge induced by spontaneous and piezoelectric polarization on $\mathrm{Ga}$ and $\mathrm{N}$ face. 
$\Delta E_{c}$ is the conduction band offset between AlGaN channel and barrier interface.

\section{Field Plate Effects and Device Optimization Characteristics}

The breakdown characteristics boosted drastically by FP employed over gate electrode towards drain side. Its characterized by electric field profile between gate and drain region. FP length varied systematically by consider specific insulator. $\mathrm{Si}_{3} \mathrm{~N}_{4}$ insulator employed to reduce trap density, reduce leakage and to increase breakdown voltage. In our simulation, $1 \mu \mathrm{m}$ field plate length assigned. As the field plate length varied, enhancement of breakdown voltage reported. No further breakdown beyond certain field plate length. Its assumed to be an material limit for Field plated analysis.

To enhance further breakdown voltage, GaN Channel replaced by AlGaN Channel material. With this technique, the maximum breakdown voltage of $1750 \mathrm{~V}$ Reported for MGFP. However, it should be noted that the peak electric field distributed for higher Vds. But trap density increased between AlGaN and Buffer region. Besides simulation performed for three Field plate devices, results clearly indicates the tradeoff between breakdown voltage and drain current. Drastic enhancement of Vbr reported in AlGaN Channel HEMT Devices.

\section{Results and Discussion}

The experimental results and proposed model results show excellent concurrence for predicting sheet carrier concentration characteristics for AlGaN channel for both $\mathrm{Ga}$ and $\mathrm{N}$ face interfaces with respect to different material compositions.

Figure 6 shows the sheet carrier concentration with barrier thickness. Barrier thickness we assumed from 19 $\mathrm{nm}$ to $80 \mathrm{~nm}$. A sheet carrier concentration much reduced because of the less strain relaxes between $\mathrm{Al}_{0.1} \mathrm{Ga}_{0.9} \mathrm{~N} /$ $\mathrm{GaN}$ interfaces. Incorporation of low $\mathrm{Al}$ about 0.05 in the channel makes less conduction band discontinuity because of less Al difference between the barrier and the channel region. Change in barrier thickness also not affected the channel much because of less Al composition. Our model much consistent with GaN based device also.

Figure 7 shows the variation of sheet carrier concentration $n_{s}$ with barrier thickness. From the results it clearly evident that AlGaN strained with GaN. As the barrier thickness increases carrier concentration also increases to $1.9 \times 10^{13} / \mathrm{cm}^{2}$. This variation of barrier thickness increases carrier concentration up to reach its critical level. Interpolation of $\mathrm{Al}$ in the channel leads to reduce the carrier density to $1.2 \times 10^{13} / \mathrm{cm}^{2}$ for the maximum barrier thickness.

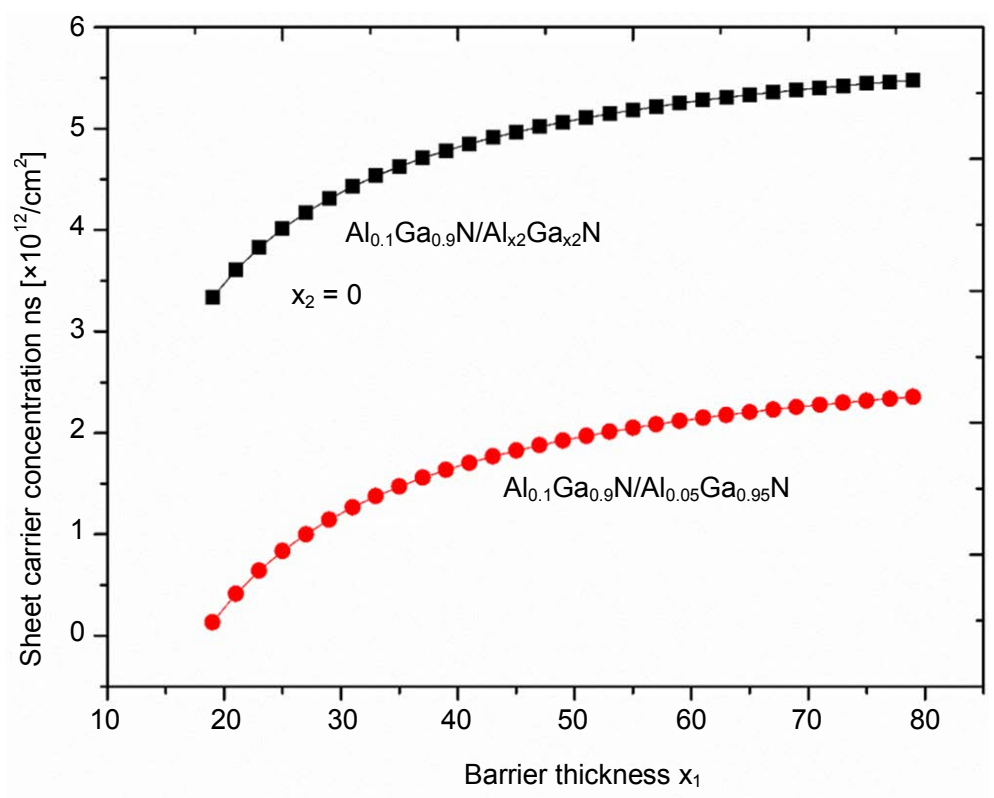

Figure 6. Sheet carrier concentration of less $\left(x_{1}=0.1, x_{2}=0\right.$ and $x_{1}=0.1, x_{2}=$ 0.05) $\mathrm{Al}$ composition in the barrier and the channel region with barrier thickness. 
Figure 8 shows the partial AlGaN with GaN. These results are considered with zero strain relax and the carrier concentration assumes to be very high, compared with the low Al composition barrier. Confined well depth increases as the $\mathrm{Al}$ composition increases. The variation of sheet carrier concentration taken for GaN channel HEMT. In this fig mole fraction $x_{2}$ varied from 0 - 0.3. For high Al difference high sheet charge density expected. Incorporation of $\mathrm{Al}$ in the channel makes the growth quality high with AlN buffer. Our model results best match with these results.

Figure 9 shows the incorporation of $\mathrm{Al}$ in $\mathrm{N}$ face $\mathrm{Al}_{0.1} \mathrm{Ga}_{0.9} \mathrm{~N} / \mathrm{Al}_{0.5} \mathrm{Ga}_{0.5} \mathrm{~N}$ device. The carrier concentration shows negative carrier density because of $\mathrm{N}$ face charge density. Modulus not taken in this plot for $\mathrm{N}$ face. Variation of sheet carrier density with barrier considered as $x_{2}$. As AlGaN channel thickness increases the confined charge shows less negative values.

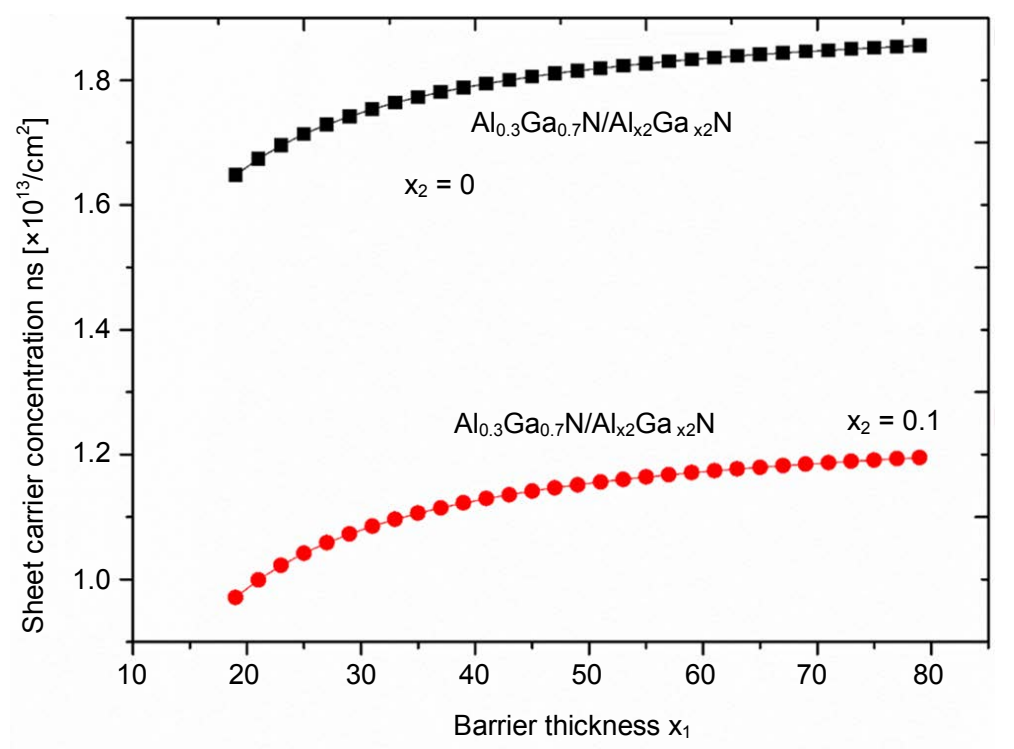

Figure 7. Charge density for moderate $\mathrm{Al}$ composition $\left(x_{1}=0.3, x_{2}=0\right.$ and $x_{1}$ $=0.3$ and $\left.x_{2}=0.1\right)$ between barrier and channel with barrier thickness.

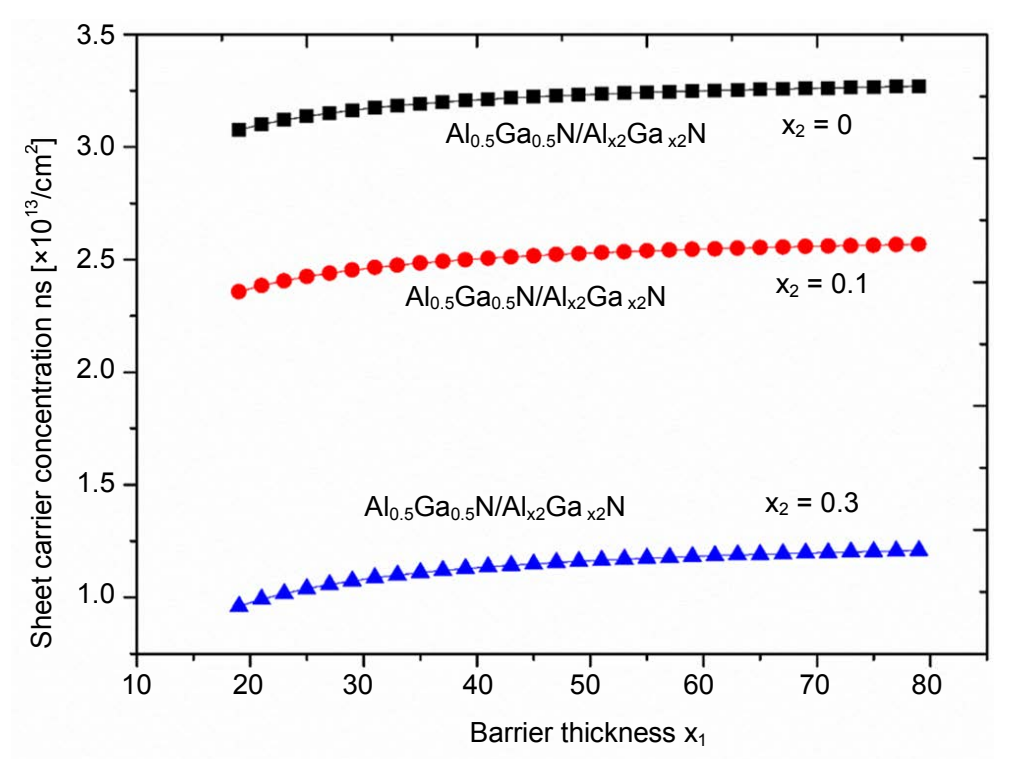

Figure 8. Sheet carrier concentration for High Al composition difference $\left(x_{1}\right.$ $=0.5, x_{2}=0, x_{1}=0.5, x_{2}=0.1$ and $x_{1}=0.5, x_{2}=0.3$ ) between barrier and channel with barrier thickness. 
Figure 10 shows the variation of sheet carrier concentration as the barrier thickness increases. The composition used here for Ga-face HFET is $\mathrm{Al}_{0.5} \mathrm{Ga}_{0.5} \mathrm{~N} / \mathrm{Al}_{0.1} \mathrm{Ga}_{0.9} \mathrm{~N}$. The Composition shows the clear evidence of incorporation of $\mathrm{Al}$ in $\mathrm{Ga}$ face heterostructures. These results shows that as the barrier thickness increases confined charge density also increased.

Figure 11 shows the comparison of experimental results published with the proposed model [4]-[10].

Figure 12 and Figure 13 show the variation of drain current with respect to drain voltage in GaN Channel and $\mathrm{Al}_{0.5} \mathrm{Ga}_{0.5} \mathrm{~N}$ channel HEMT. It's verified with GaN buffer, $\mathrm{Al}_{0.1} \mathrm{Ga}_{0.9} \mathrm{~N}$ Back Barrier (BB), $\mathrm{Al}_{0.1} \mathrm{Ga}_{0.9} \mathrm{~N}$ BB \& MGFP1 and $\mathrm{Al}_{0.05} \mathrm{Ga}_{0.95} \mathrm{~N}$ BB \& $\mathrm{Al}_{0.1} \mathrm{Ga}_{0.9} \mathrm{~N}$ BB \& MGFP2.

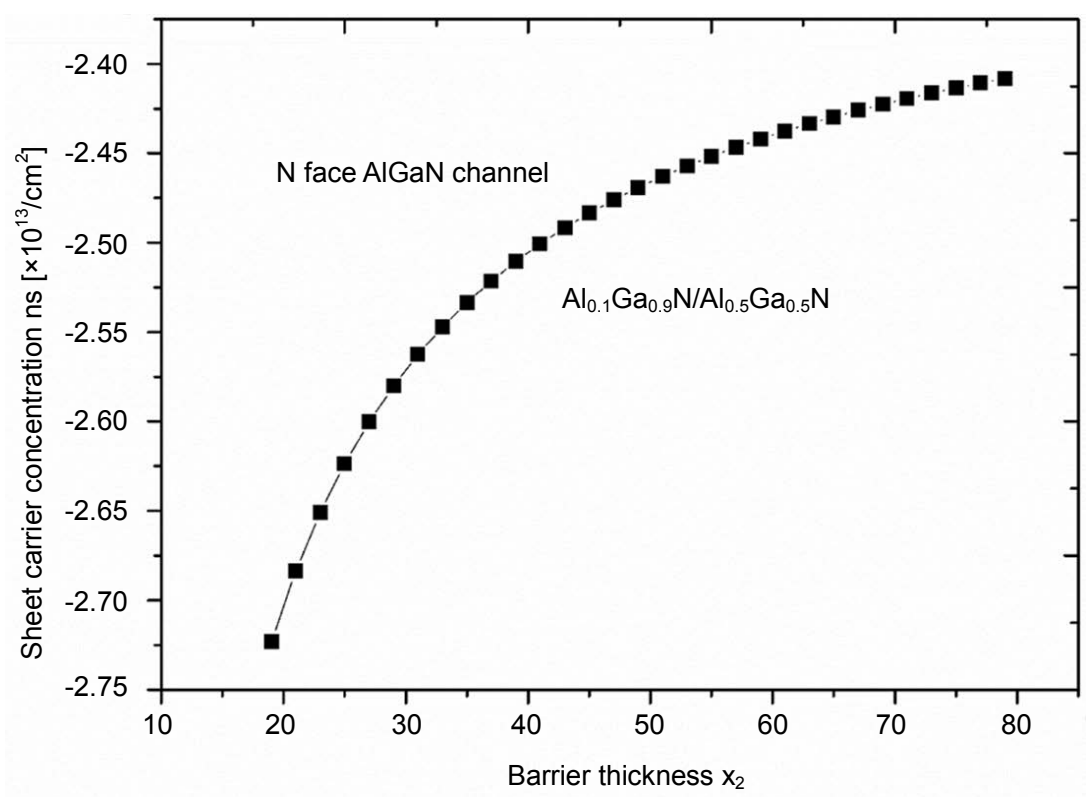

Figure 9. Variation of carrier concentration in the $\mathrm{N}$ face $\mathrm{AlGaN}$ channel with barrier thickness. Assumed $x_{1}=0.1$ and $x_{2}=0.5$.

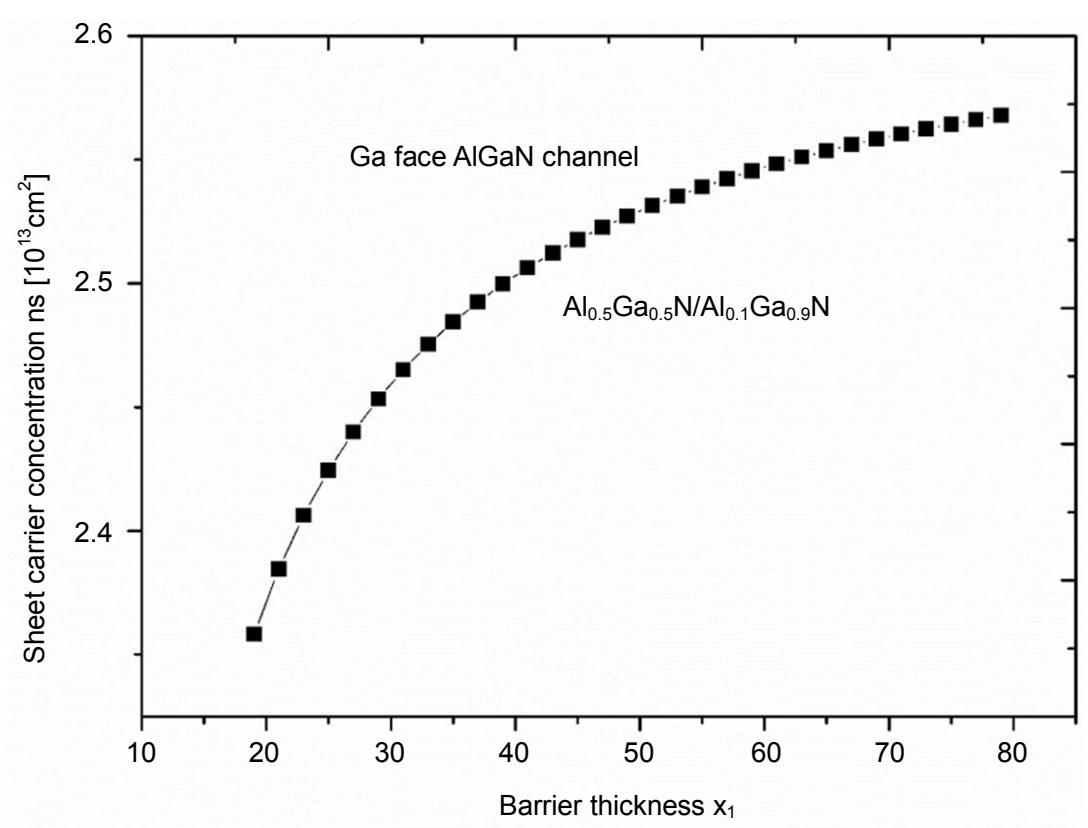

Figure 10. Change of Sheet carrier concentration in Ga face AlGaN channel with barrier thickness. Assumed $x_{1}=0.5$ and $x_{2}=0.1$. 


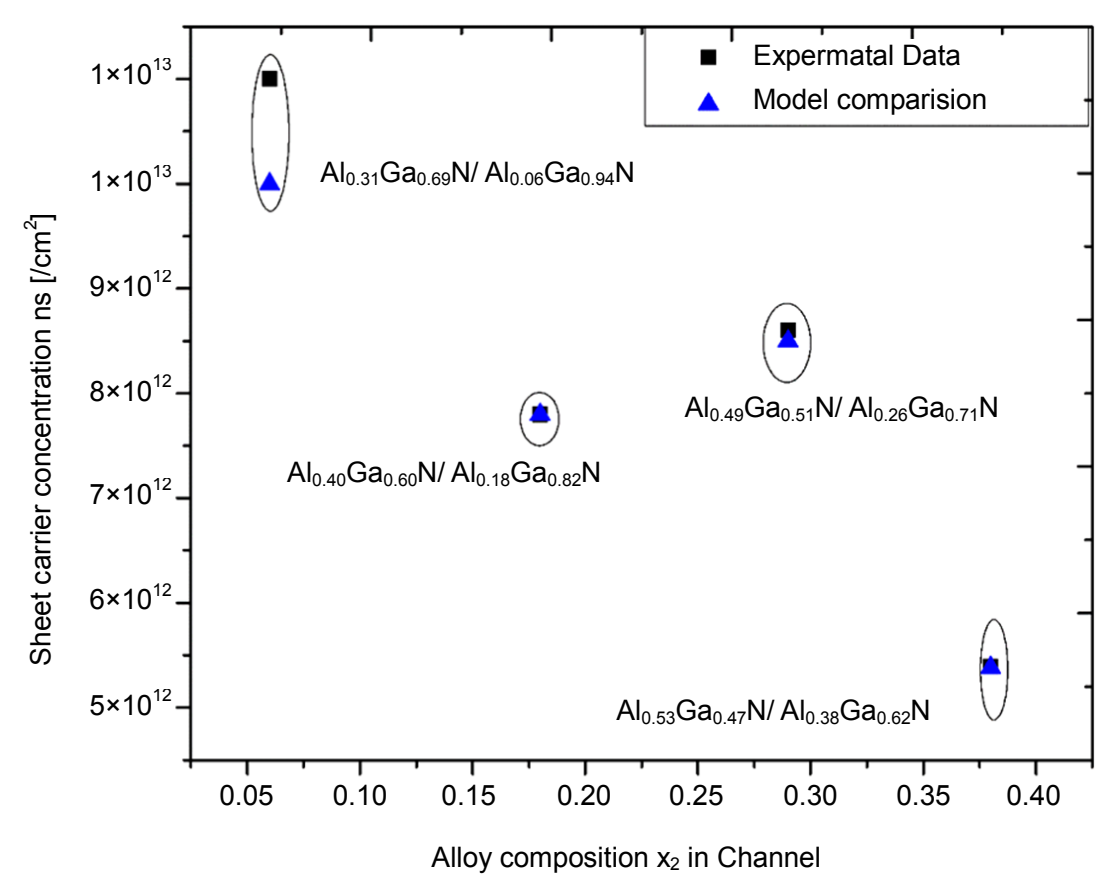

Figure 11. Experimental verification of reported AlGaN channel results with proposed sheet carrier density model [10].

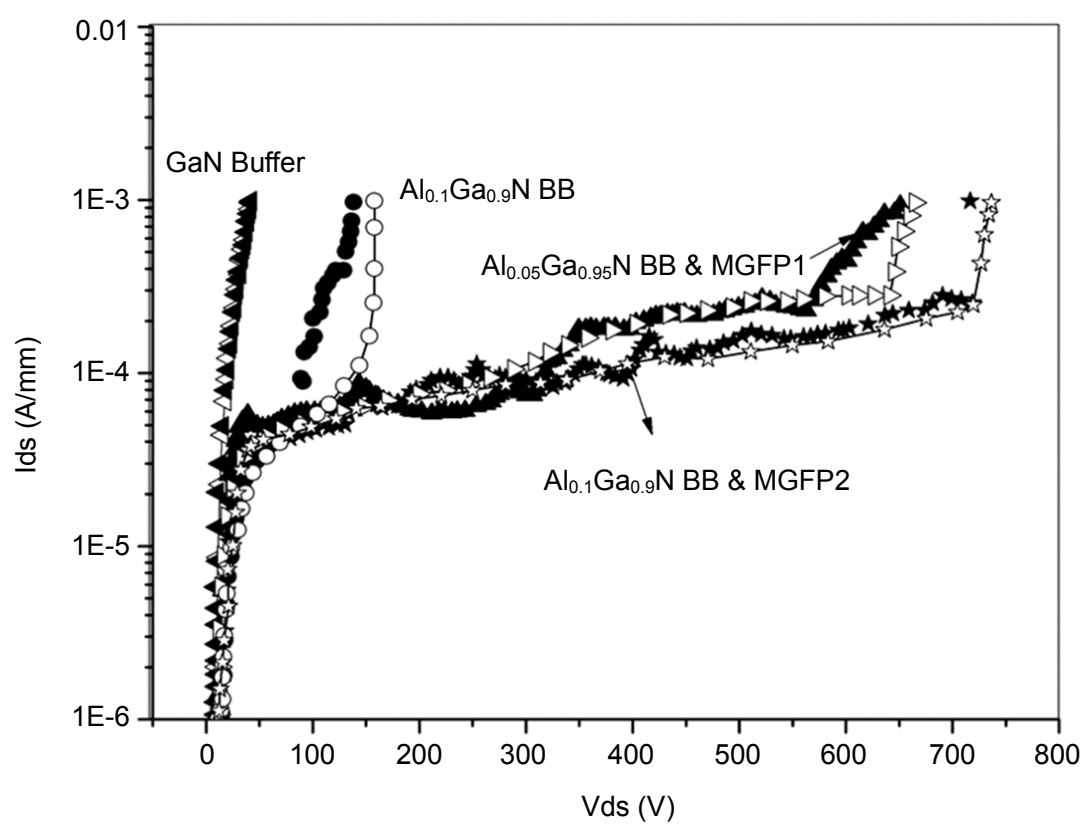

Figure 12. Variation of OFF state drain voltage with drain current. Filled box represents Experimental and empty box represents Simulation validated data.

\section{Conclusion}

We have analyzed the formation of 2DEG charge density for various alloy compositions in AlGaN barrier and channel interface regions. The above results were analyzed for both $\mathrm{Ga}$ and $\mathrm{N}$ face interfaces. Polarization charge density in the AlGaN channel from low to high $\mathrm{Al}$ interpolation was analyzed in detail. From the results, it shows that calculated 2DEG carrier concentration exhibits good agreement with experiment reported values. Incorporation of strain relaxation is essential in AlGaN channel because of AlN buffer. From the relaxation model, 


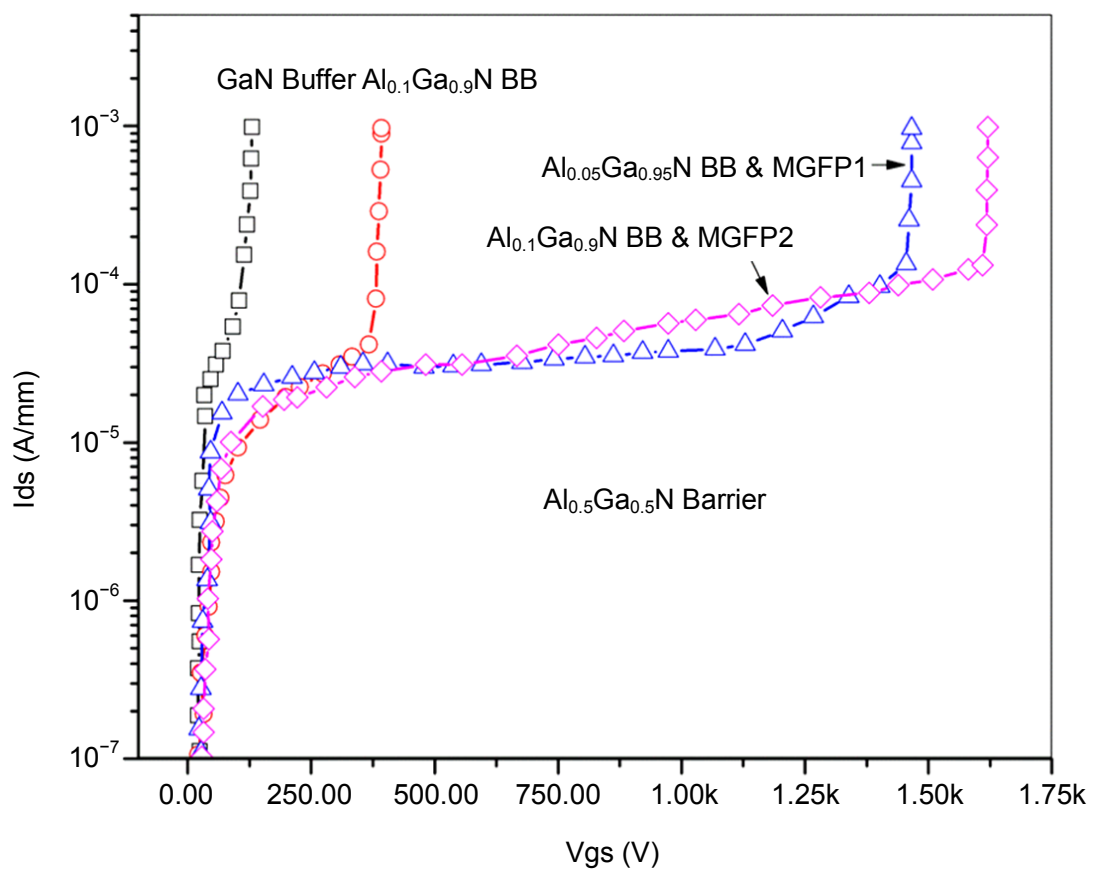

Figure 13. Enhancement of OFF State breakdown voltage with drain current for AlGaN channel HEMTs.

adding Al composition in Channel leads to create strain relaxation in barrier. Our theoretical results prove that incorporation of $\mathrm{Al}$ makes device possible for future high power and high frequency application.

\section{Acknowledgements}

The authors thank the Council of Scientific and Industrial Research for financially supporting this research.

\section{References}

[1] Chung, J.W., Hoke, W.E., Chumbes, E.M. and Palacios, T. (2010) AlGaN/GaN HEMT With 300-GHz $f_{\max }$. IEEE Electron Device Letters, 31, 195-197. http://dx.doi.org/10.1109/LED.2009.2038935

[2] Wu, Y.F., Saxler, A., Moore, M., Smith, R.P., Sheppard, S., Chavarkar, P.M., Wisleder, T., Mishra, U.K. and Parikh, P. (2004) 30-W/mm GaN HEMTs by Field Plate Optimization. IEEE Electron Device Letters, 25, 117-119. http://dx.doi.org/10.1109/LED.2003.822667

[3] Hashimoto, S., Akita, K., Tanabe, T., Nakahata, H., Takeda, K. and Amano, H. (2010) Epitaxial Layers of AlGaN Channel HEMTson AIN Substrates. SEI Technical Review, 71, 83.

[4] Raman, A., Dasgupta, S., Rajan, S., Speck, J.S. and Mishira, U.K. (2008) AlGaN Channel High Electron Mobility Transistors: Device Performance and Power-Switching Figure of Merit. Japanese Journal of Applied Physics, 47, 3359. http://dx.doi.org/10.1143/JJAP.47.3359

[5] Nanjo, T., Takeuchi, M., Suita, M., Abe, Y., Oishi, T., Tokuda, Y. and Aoyagi, Y. (2008) First Operation of A1GaN Channel High Electron Mobility Transistors. Applied Physics Express, 1, Article ID: 011101. http://dx.doi.org/10.1143/APEX.1.011101

[6] Nanjo, T., Takeuchi, M., Suita, M., Abe, Y., Oishi, T., Abe, Y., Tokuda, Y. and Aoyagi, Y. (2008) Remarkable Breakdown Voltage Enhancement in AlGaN Channel high Electron Mobility Transistors. Applied Physics Letters, 92, Article ID: 263502. http://dx.doi.org/10.1063/1.2949087

[7] Nanjo, T., Suita, M., Oishi, T., Abe, Y., Yagyu, E. and Tokuda, Y. (2009) Comparison of the Characteristics of the AlGaN Channel HEMTs Formed on SiC and Sapphire Substrates. Electronics Letters, 45, 424. http://dx.doi.org/10.1049/el.2009.0129

[8] Jeon, C.M. and (2004) The Improvement of DC Performance in AlGaNGaN HEFTs With Isoelectronic Al-Doped Channels. IEEE Electron Device Letters, 25, 120-122. http://dx.doi.org/10.1109/LED.2004.824246

[9] Liu, J., Zhou, Y., Chu, R., Cai, Y., Chen, K.J. and Lau, K.M. (2004) $\mathrm{Al}_{0.3} \mathrm{Ga}_{0.7} \mathrm{~N} / \mathrm{Al}_{0.05} \mathrm{Ga}_{0.95} \mathrm{~N} / \mathrm{GaN}$ Compos- 
ite-Channel HEMTs with Enhanced Linearity. International Electron Devices Meeting (IEDM), 811.

[10] Liu, J., Zhou, Y., Chu, R., Cai, Y., Chen, K.J. and Lau, K.M. (2005) Highly Linear $\mathrm{Al}_{0.3} \mathrm{Ga}_{0.7} \mathrm{~N}-\mathrm{Al}_{0.05} \mathrm{Ga}_{0.95} \mathrm{~N}-\mathrm{GaN}$ Composite-Channel HEMTs. IEEE Electron Device Letters, 26, 145-147. http://dx.doi.org/10.1109/LED.2005.843218

[11] Bajaj, S., Hung, T.-H., Akyol, F., Nath, D. and Rajan, S. (2014) Modeling of High Composition AlGaN Channel High Electron Mobility Transistors with Large Threshold Voltage. Applied Physics Letters, 105, Article ID: 263503. http://dx.doi.org/10.1063/1.4905323

[12] Ha, W., Zhang, J.-C., Zhao, S.-L., Ge, S.-S., Wen, H.-J., Zhang, C.-F., Ma, X.-H. and Hao, Y. (2013) AlGaN Channel High Electron Mobility Transistors with Ultra-Low Drain-Induced-Barrier-Lowering Coefficient. Chinese Physics Letters, 30, Article ID: 127201. http://dx.doi.org/10.1088/0256-307X/30/12/127201

[13] Hashimoto, S., Akita, K., Tanabe, T., Nakahata, H., Takeda, K. and Amano, H. (2010) Sublimation Growth of Nonpolar AIN Single Crystals and Defect Characterization. Physica Status Solidi (C), 7, 1767-1769. http://dx.doi.org/10.1002/pssc.200983590

[14] Hatano, M., Kunishio, N., Chikaoka, H., Yamazaki, J., Makhzani, Z.B., Yafune, N., Sakuno, K., Hashimoto, S., Akita, K., Yamamoto, Y. and Kuzuhara, M. (2010) Comparative High-Temperature DC Characterization of HEMTs with GaN and AlGaN Channel Layers. CS MANTECH Conference, 17-20 May 2010, Portland.

[15] Tokuda, H., Hatano, M., Yafune, N., Hashimoto, S., Akita, K., Yamamoto, Y. and Kuzuhara, M. (2010) High Al Composition AlGaN-Channel High-Electron-Mobility Transistor on AlN Substrate. Applied Physics Express, 3, Article ID: 121003. http://dx.doi.org/10.1143/APEX.3.121003

[16] Ambacher, O., Smart, J., Shealy, J.R., Weimann, N.G., Chu, K., Murphy, M., Schaff, W.J. and Eastman, L.F. (1999) Two-Dimensional Electron Gases Induced by Spontaneous and Piezoelectric Polarization Charges in N- and Ga-Face AlGaN/GaN Heterostructures. Journal of Applied Physics, 85, 3222. http://dx.doi.org/10.1063/1.369664

[17] Asai, T., Nagata, K., Mori, T., Nagamatsu, K., Iwaya, M., Kamiyama, S., Amano, H. and Akasaki, I. (2009) Relaxation and Recovery Processes of $\mathrm{Al}_{\mathrm{x}} \mathrm{Ga}_{1-\mathrm{x}} \mathrm{N}$ Grown on AlN Underlying Layer. Journal of Crystal Growth, 311, $2850-2852$. http://dx.doi.org/10.1016/j.jcrysgro.2009.01.028 